Submitted to Acta Cryst. C

\title{
Two stereoisomers of the rat toxicant norbormide
}

\author{
Peter J. Steel ${ }^{\mathrm{a}}$, Margaret A. Brimble ${ }^{\mathrm{b}}$, Brian Hopkins ${ }^{\mathrm{c}}$ and David Rennison ${ }^{\mathrm{b}}$
}

${ }^{\mathbf{a}}$ Department of Chemistry, University of Canterbury, Christchurch, New Zealand, ${ }^{\mathbf{b}}$ Department of Chemistry, University of Auckland, 23 Symonds St., Auckland, New Zealand, and ' Landcare Research, Mt Albert Research Centre, Mt Albert Road, Private Bag 92170 , Auckland, New Zealand

Correspondence email: peter.steel@canterbury.ac.nz

\begin{abstract}
The structures of two diastereoisomers of norbormide $\left(\mathrm{C}_{33} \mathrm{H}_{25} \mathrm{~N}_{3} \mathrm{O}_{3}\right.$, one as an ethyl acetate hemi-solvate $\mathrm{C}_{33} \mathrm{H}_{25} \mathrm{~N}_{3} \mathrm{O}_{3} \cdot 0.5\left(\mathrm{C}_{4} \mathrm{H}_{8} \mathrm{O}_{2}\right)$ have been unambiguously determined. They differ in the relative stereochemistry of the exocyclic double bond and the relative conformations of the aryl rings. Each is involved in both intra- and inter-molecular hydrogen bonding.
\end{abstract}

\section{Comment}

AUTHOR: Please check that the Bova references $(2001 a, 2001 b)$ are correctly identified. *Yes they are*

Norbormide is a compound discovered in the early $1960 \mathrm{~s}$ that is selectively toxic to rats and relatively harmless to other rodents and mammals (Roszkowski, 1965). It exerts its lethality in the rat through mechanisms involving the control of blood pressure. Evidence suggests that norbormide acts by stimulating a number of signal transduction pathways that lead to modulation of calcium influx, presumably mediated by cell membrane receptor(s) (Bova et al., 2001a). Physiological studies indicate that norbormide elicits divergent tissue responses, causing selective vasoconstriction of small arteries and vasodilation of large blood vessels in the rat, whilst dilating both small and large blood vessels of other species (Bova et al., 2001b).

We recently synthesized and purified six of the eight racemic diastereoisomers of norbormide and undertook a structure-activity relationship study of these isomers with respect to vasorelaxant and vasoconstrictor properties (Brimble et al., 2003). These isomers differ according to the stereochemistry (cis/trans) of the exocyclic double bond, the orientation (endo/exo) of the maleimide ring and the stereochemistry (erythro/threo) of the tertiary alcohol. The contrasting responses of the different isomers to this toxin may be the key to understanding the secret of species-specificity of drug action and provides opportunities for developing more species-selective pesticides.

Our initial work in this area (Brimble et al., 2003) established that the cis-endo-threo isomer (1a) of norbormide exhibited the most potent vasoconstrictor properties and is a lead compound for analogue development. We herein report the crystal structures of the cis-endo-threo isomer (1a) and the trans-endo-threo isomer ( $1 \mathrm{~b}$ ) of norbormide in order to unambiguously confirm their structures and to facilitate molecular modelling studies for the construction of analogues. At the outset of this work only a crystal structure of the $N$-bromobenzyl derivative of (1a) was available (Abrahamsson \& Nilsson, 1966) and we were keen to obtain the three-dimensional coordinates for the parent compounds. 


\section{Acta C preprint}

[Structures of (1a) and (1 b) here]

Figure 1 shows a perspective view of the structure of isomer (1a), which crystallizes in the monoclinic space group $P 2{ }_{1} / n$. This unambiguously confirms that the most potent isomer is indeed that in which the exocyclic double bond has the 2-pyridyl substituent cis to the diarylmethanol substituent, which has threo stereochemistry, and the maleimide ring has an endo configuration. Within the molecule the hydroxyl group is involved in an intramolecular hydrogen bond to the adjacent pyridine ring (Table 1). Intermolecular interactions form centrosymmetric pairs of linear H-bonds [graph set notation $R^{2}{ }_{2}(8)$ ] between the $\mathrm{NH}$ and $\mathrm{O} 3$ of the maleimide groups (Table 1). AUTHOR: Please check additon to last sentence. *Correct*

[Figure 1 and Table 1 here]

Figure 2 shows the structure of isomer $(1 \mathrm{~b})$, which crystallizes in the monoclinic space group P2/c along with half a solvate molecule of ethyl acetate, which is disordered about a 2 -fold rotation axis. This isomer differs from (1a) in having the opposite stereochemistry of the exocyclic double bond. That is, the pyridine ring, involving N31, has a trans relationship relative to the diarylmethanol substituent. Another difference between the two structures is that the four aryl (phenyl and 2-pyridyl) substituents have very different torsional orientations. Once again the $\mathrm{OH}$ group is involved in an intramolecular H-bond to N11. However, in this case the hydrogen bonding is bifurcated with an additional, albeit weaker, interaction with $\mathrm{O} 3$ of the maleimide ring (Table 2). Adjacent molecules are again connected by linear intermolecular H-bonds involving the maleimide groups, [graph set notation $R^{2}{ }_{2}(8)$ ] although in this case the molecules are related by a twofold axis (Table 2). AUTHOR: Please check the assertion about the glide plane in the last sentence. I think the molecules are related by a twofold axis $(-x, y, 0.5-z)$. *You are absolutely correct. My apologies for this inexcusable error!* Also approve the addition. *Okay*

[Figure 2 and Table 2 here]

During the course of this work we also indirectly confirmed the structure of a third isomer. Several datasets were collected using crystals of isomer (1a) contaminated with varying amounts of another isomer. In each case the isomer ratio was independently determined by ${ }^{1} \mathrm{H}$ NMR and was found to vary between 2:1 and 4:1. These crystals were all isomorphous with those of pure (1a) (see above) and refined with disorder of the two aryl rings attached to the tertiary alcohol centre. Specifically the rings attached to that centre had different conformations, presumably as a consequence of a different hydrogen bonding pattern. This therefore identified the minor component as the cis-endo-erythro isomer.

\section{Experimental}

The title compounds were prepared, and recrystallized from ethyl acetate, as described previously (Brimble et al., 2003).

\section{Refinement}

AUTHOR: Please confirm the following re-wording is correct *Yes*

Crystal decay was monitored by the measurement of duplicate reflections and was found to be negligible. $\mathrm{OH}$ and $\mathrm{NH}$ $\mathrm{H}$ atoms were located from difference Fourier syntheses and their positions refined, with an $\mathrm{N}-\mathrm{H}$ bond length restraint of $0.95(2) \AA$ in isomer $1 \mathrm{~b}$, and with $U_{\text {iso }}(\mathrm{H})=1.5 U_{\text {eq }}(\mathrm{N})$. $\mathrm{CH}$ H atoms were placed in calculated positions, with $\mathrm{C}-\mathrm{H}$ 
distances set at $0.95 \AA$ (aryl and alkene $\mathrm{H}$ ) or $1.00 \AA$ (methine $\mathrm{H}$ ), and refined as riding, with $U_{\text {iso }}(\mathrm{H})=1.2 U_{\text {eq }}(\mathrm{C})$, except for the solvate methyl $\mathrm{H}$ atoms which have $U_{\text {iso }}(\mathrm{H})=1.5 U_{\text {eq }}(\mathrm{C})$.

AUTHOR: fine-focus or normal-focus sealed tube? *Fine-focus, as stated below*

\section{Computing details}

For both compounds, data collection: Bruker SMART (Bruker, 1997); cell refinement: Bruker SAINT (Bruker, 1997); data reduction: Bruker SAINT; program(s) used to solve structure: SHELXS97 (Sheldrick, 1990); program(s) used to refine structure: SHELXL97 (Sheldrick, 1997); molecular graphics: Bruker SHELXTL ((Bruker, 1997)); software used to prepare material for publication: Bruker SHELXTL

\section{Figures}

Figure 1. Perspective view and atom-numbering scheme of 1a. The wholly obscured atom C45 is not labelled. Displacement ellipsoids are drawn at the $30 \%$ probability level.

Figure 2. Perspective view and atom-numbering scheme of $1 \mathrm{~b}$. Displacement ellipsoids are drawn at the $30 \%$ probability level. The disordered ethyl acetate solvate molecule is not shown.

\section{(1a)}

\section{Crystal data}

$\mathrm{C}_{33} \mathrm{H}_{25} \mathrm{~N}_{3} \mathrm{O}_{3}$

$M_{r}=511.56$

Monoclinic, $P 2{ }_{1} / n$

$a=15.433$ (4) $\AA$

$b=11.437$ (3) $\AA$

$c=17.048(5) \AA$

$\beta=115.427(3)^{\circ}$

\section{Data collection}

Bruker SMART CCD area detector diffractometer

Absorption correction: multi-scan (SADABS; Sheldrick, 2002)

$T_{\min }=0.744, T_{\max }=1.000$

28763 measured reflections

\section{Refinement}

$R\left[F^{2}>2 \sigma\left(F^{2}\right)\right]=0.041$

$w R\left(F^{2}\right)=0.102$

$S=1.08$

4795 reflections

$$
\begin{aligned}
& V=2717.6(13) \AA^{3} \\
& Z=4 \\
& \text { Mo } K \alpha \\
& \mu=0.08 \mathrm{~mm}^{-1} \\
& T=163(2) \mathrm{K} \\
& 0.59 \times 0.48 \times 0.04 \mathrm{~mm}
\end{aligned}
$$

4795 independent reflections

3147 reflections with $I>2 \sigma(I)$

$R_{\text {int }}=0.049$

358 parameters

$\mathrm{H}$ atoms treated by a mixture of independent and constrained refinement

$\Delta \rho_{\max }=0.15$ e $\AA^{-3}$

$\Delta \rho_{\min }=-0.19$ e $\AA^{-3}$ 


\section{Acta C preprint}

Hydrogen-bond geometry $\left(A,{ }^{\circ}\right)$

$\begin{array}{lllll}D-\mathrm{H} \cdots A & D-\mathrm{H} & \mathrm{H} \cdots A & D \cdots A & D-\mathrm{H} \cdots A \\ \mathrm{O} 1-\mathrm{H} 1 \mathrm{~B} \cdots \mathrm{N} 11 & 0.79(2) & 2.12(3) & 2.645(2) & 125(2) \\ \mathrm{N} 1-\mathrm{H} 1 \mathrm{C} \cdots \mathrm{O} 3^{\mathrm{i}} & 0.95(2) & 2.02(2) & 2.965(2) & 174(2)\end{array}$

Symmetry codes: (i) $-x,-y+1,-z+2$.

(1b)

Crystal data

$\mathrm{C}_{33} \mathrm{H}_{25} \mathrm{~N}_{3} \mathrm{O}_{3} \cdot 0.5\left(\mathrm{C}_{4} \mathrm{H}_{8} \mathrm{O}_{2}\right)$

$M_{r}=555.61$

Monoclinic, $P 2 / c$

$a=17.999$ (3) $\AA$

$b=12.614$ (2) $\AA$

$c=13.063(2) \AA$

$\beta=110.834(2)^{\circ}$

$$
\begin{aligned}
& V=2771.9(8) \AA^{3} \\
& Z=4 \\
& \text { Mo } K \alpha \\
& \mu=0.09 \mathrm{~mm}^{-1} \\
& T=173(2) \mathrm{K} \\
& 0.48 \times 0.12 \times 0.08 \mathrm{~mm}
\end{aligned}
$$

\section{Data collection}

Bruker SMART CCD area detector diffractometer

Absorption correction: multi-scan (SADABS; Sheldrick, 2002)

$T_{\min }=0.738, T_{\max }=1.000$

4870 independent reflections

1989 reflections with $I>2 \sigma(I)$

$R_{\text {int }}=0.159$

31232 measured reflections

\section{Refinement}

$R\left[F^{2}>2 \sigma\left(F^{2}\right)\right]=0.062$

$w R\left(F^{2}\right)=0.125$

$S=0.89$

4870 reflections

396 parameters

1 restraint

$\mathrm{H}$ atoms treated by a mixture of independent and constrained refinement

$\Delta \rho_{\max }=0.21 \mathrm{e} \AA^{-3}$

$\Delta \rho_{\min }=-0.23$ e $\AA^{-3}$

Hydrogen-bond geometry $\left(A,{ }^{\circ}\right)$

$D-\mathrm{H} \cdots A$

O1-H1B $\cdots \mathrm{N} 11$

$\mathrm{O} 1-\mathrm{H} 1 \mathrm{~B} \cdots \mathrm{O} 3$

$\mathrm{N} 1-\mathrm{H} 1 \mathrm{C} \cdots \mathrm{O} 2^{\mathrm{i}}$

Symmetry codes: (i) $-x+1, y,-z+1 / 2$.

$\begin{array}{llll}D-\mathrm{H} & \mathrm{H} \cdots A & D \cdots A & D-\mathrm{H} \cdots A \\ 0.93(3) & 2.30(3) & 2.765(4) & 111(3) \\ 0.93(3) & 2.33(3) & 2.917(3) & 121(3) \\ 0.92(3) & 1.94(3) & 2.863(4) & 175(3)\end{array}$




\section{References}

AUTHOR: Please check that the Bova references (2001a, 2001b) are correctly identified. *Yes, this is correct* Abrahamsson, S. \& Nilsson, B. (1966). J. Org. Chem. 31, 3631-3634.

Bova, S., Trevisi, L., Cima, L., Luciani, S., Golovina, V. \& Cargnelli, G. (2001a). J. Pharm. Exp. Ther. 296, 458-463.

Bova, S., Cima, L., Golovina, V., Luciani, S. \& Cargnelli, G. (2001b). Cardiovasc. Drug Rev. 19, 226-233.

Brimble, M. A., Muir, V., Hopkins, B. \& Bova, S. (2003). Arkivoc, in press.

Bruker (1997). SMART, SAINT and SHELXTL. Area Detector Control and Integration Software. Siemens Analytical X-ray Instruments Inc., Madison, Wisconsin, USA.

Mohrbacher, R. J., Almond, H. R., Carson, E. L., Rosenau, J. D. \& Poos, G. I. (1966). J. Org. Chem. 31, 2141-2148.

Roszkowski, A. P. (1965). J. Pharm. Exp. Ther. 149, 288-299.

Sheldrick, G. M. (1990). Acta Cryst. A46, 467-473.

Sheldrick, G. M. (2002). SADABS. Version 2.03. University of Göttingen, Germany.

Sheldrick, G. M. (1997). SHELXL97. University of Göttingen, Germany.

AUTHOR: References (AUTHOR, YEAR) have been added to the _computing_‥ data items. Please check they are now correct. *Yes* 